\title{
6 Economic Impact of Soil Salinization and the Potential for Saline Agriculture
}

\author{
Eric Ruto, Domna Tzemi, lain \\ Gould, and Gary Bosworth
}

\section{CONTENTS}

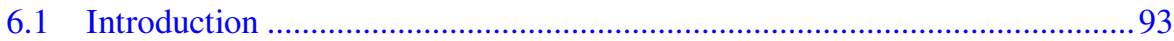

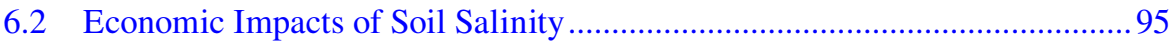

6.3 Methodological Framework to Assessing Economic

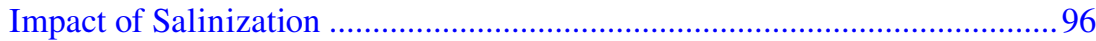

6.3.1 Overall Approach and Conceptual Framework ....................................96

6.3.2 Salinity Processes and Scenarios ..........................................................98

6.3.3 Economic Model: Impact of Salinity on Crop
Yield and Output............................................................................. 100

6.4 Results and Discussion: Economic Impacts of Salinization........................... 101

6.4.1 Farm-Level Economic Impacts of Salinization................................. 101

6.4.1.1 Impacts of Irrigation Salinization......................................... 101

6.4.1.2 Impacts of Seepage Salinization........................................... 103

6.4.1.3 Impacts of Flood Salinization............................................. 103

6.4.2 Regional Economic Impact of Salinization......................................... 104

6.4.2.1 Case Studies from Europe's North Sea Region ................... 106

6.4.2.2 Regional Impact of Flood Salinization:

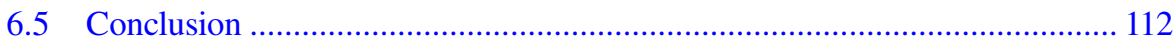

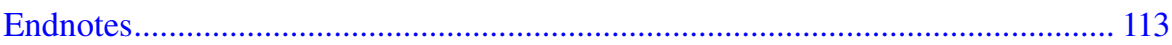

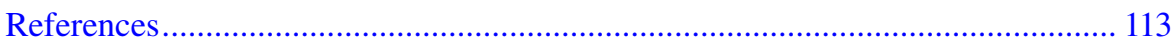

\subsection{INTRODUCTION}

Soil salinization, defined as the accumulation of water-soluble salts in the soil to a level that impacts on agricultural production, environmental health, and economic welfare (FAO 2011), is a global problem and one of the major causes of land degradation. A major United Nations Environment Programme (UNEP) study GLASOD (Global Assessment of Soil Degradation), which was a first 
attempt to produce a world map on the status of human-induced soil degradation, identified soil salinization as one of the major types of soil degradation (Oldeman et al. 1991).

The drivers or types of soil salinization have generally been characterized as either primary or secondary (Daliakopoulos et al. 2016). Primary salinization is the accumulation of salts in the soil profile through natural processes. Secondary (or human-induced) salinization, on the other hand, is driven by human interventions, mainly irrigation with saline water often coupled with poor drainage systems, overexploitation of groundwater and seawater ingress into coastal land that may be exacerbated by climate change and sea-level rise.

Soil salinization is a significant constraint to agricultural production globally. For example, FAO and ITPS (2015) estimates that increasing soil salinity problems are taking up to 1.5 million ha of farmland out of agricultural production each year and compromising the yield potential of a further 20 to 46 million ha. Furthermore, projected changes associated with climate change are likely to exacerbate the risks associated with salinization (Koutroulis et al. 2013). Climate change is also expected to lead to a reduction in potential yields of major crops (such as wheat) around the world which has implications for global food security. Food security is an important policy issue as espoused by UN Sustainable Development Goals (SDGs): "End hunger, achieve food security and improved nutrition and promote sustainable agriculture" (SDG 2) (UN 2015). Lipper et al. (2014) posit that the expansion of the level of agricultural output will require greater use of inputs at an increasing cost and innovations in "climate-smart" agricultural practices such as saline farming.

Despite the significance of soil salinization, there is sparse information on its impact on agriculture (and economies) in Europe and globally. This is partly because of the unavailability of reliable data on the extent and severity of salinization, which limits the biophysical modelling of impacts of salinization and concomitant economic impacts. For example, industry and policymakers need information on the economic costs of salinization to guide investment decisions and strategies for the amelioration of salinization related impacts and to set priorities for innovative adaptation strategies such as the development of saline agriculture.

The aim of the chapter is to provide a framework for economic risk assessment in regions where salinity poses a significant threat to agricultural production and the local/national economy. The analysis of the costs of salinization should provide a "baseline" for economic impacts of salinization (on agriculture and the wider economy) which helps to inform the assessment of adaptation measures including the potential for saline agriculture. This topic remains largely unaddressed by the literature and this chapter helps to fill in a significant gap.

The rest of the chapter is structured as follows. Section 6.2 reviews key literature on economic impacts of soil salinity. Section 6.3 presents our conceptual and methodological framework for assessing the economic costs of salinization. This leads to Section 6.4 in which we present empirical results of farm-level, regional (case study) and wider economy impacts of salinity, structured around a typology of salinization processes (irrigation, seepage and flood salinization). Section 6.5 concludes the chapter. 


\subsection{ECONOMIC IMPACTS OF SOIL SALINITY}

The biophysical effects (e.g. yield losses) of soil salinization are relatively well documented. Although there is a wide variation between and within crop types, farm-level studies show crop yield losses on salt-affected lands of 40-63\% in India, 36-69\% in Pakistan and 71-86\% in Kazakhstan (Qadir et al. 2014).

One of the first studies on global costs of salinity was conducted by Ghassemi et al. (1995), who assessed that the global income losses due to salinity at about USD 11.4 billion per year in irrigated areas and USD 1.2 billion per year in non-irrigated areas. Building on Ghassemi et al. (1995), a comprehensive meta-analysis conducted by Qadir et al. (2014) estimated the annual (inflation adjusted) income losses from salt-affected irrigated areas as USD 27.3 billion, based mainly on crop yield losses. The authors based their calculations on an Food and Agriculture Organization of the United Nations (FAO) estimated globally irrigated area of 310 million hectares (Mha) (FAO 2011) with an estimated $20 \%$ of this area being salt affected (62 Mha). Based on these estimates, the annual cost of salinity related land degradation was approximated as USD 441 per ha in 2013. It is noted, however, that these estimates on the global cost of salinized land degradation are mainly based on crop yield losses. These costs are expected to be even higher when other cost components are taken into consideration, such as the environmental costs associated with salt-affected lands and the potential social cost on farm businesses. On the other hand, adaptation measures such as the use of salt-tolerant crops may be expected to ameliorate some of the impacts of salinization.

Economic studies on the impact of soil salinization in Europe are limited. One of the early studies in Europe was conducted by Zekri and Albisu (1993) who studied the economic effect of salinity at the farm level in Berdenas, an area of 56,760 ha of irrigated land situated north of Zaragoza and south of Navarra in Spain. The objectives of the research were to assess soil salinity levels, to simulate the future situation without the effects of salinity and to estimate soil reclamation costs and benefits. They employed an interactive multi-objective mathematical programming methodology, optimizing three different objectives: (a) maximizing total farm gross margin, (b) maximizing labor used and (c) minimizing labor seasonality in order to avoid periods of unemployment during the year and minimizing risk. The study showed considerable benefits from soil reclamation at a level equivalent to 69 million $€$, with 799 jobs generated. More recently, a study conducted by Montanarella (2007) in three European countries (Spain, Hungary and Bulgaria) estimated annual costs of soil salinization in the range of €158-321 million, mainly as a result of agricultural yield losses.

A review of the literature shows that most studies focus on the cost of salinity in irrigation systems. A majority of these studies estimate the cost of salinization from biophysical output losses (mainly crop yield losses) for a range of salt-affected irrigation lands (Qadir et al. 2014). However, some economic studies take account of additional costs (e.g. remediation of salt degraded land) or additional inputs (and costs) used to mitigate some of the impacts of salt related land degradation, which would otherwise not be used for non-degraded land. The consensus in the literature is that preventing salinization would result in considerable savings, mainly from reduced yield losses and opportunity costs. 


\section{TABLE 6.1 \\ Economic Costs of Salt-Induced Land Degradation in Different Parts of the World}

\begin{tabular}{lllc}
$\begin{array}{l}\text { Study Authors } \\
\text { Marshall and Jones (1997) }\end{array}$ & $\begin{array}{l}\text { Country } \\
\text { Australia }\end{array}$ & $\begin{array}{c}\text { Methodology } \\
\text { Opportunity costs based on dose } \\
\text { response method and mitigation costs }\end{array}$ & $\begin{array}{c}\text { Equivalent in Million } \\
\text { USD Year }\end{array}$ \\
Janmaat (2004) & India & $\begin{array}{c}\text { Opportunity costs (forgone } \\
\text { agricultural income) }\end{array}$ & 46 \\
Marshall (2004) & Australia & Transaction costs & 20.03 \\
John et al. (2005) & Australia & Opportunity costs \\
Aslam and Prathapar (2006) & Pakistan & Opportunity costs & 0.09 \\
McCann and Hafdahl (2007) & Australia & Transaction costs & 267 \\
Winpenny et al. (2010) & Spain & Mitigation costs & 102 \\
Source: Negacz (2018). & & & 810 \\
& & & \\
\hline
\end{tabular}

Table 6.1 summarizes estimates of economic costs (yield loss and additional costs) of salinity in different parts of the world. As may be expected, most studies on the economic impact of salt-induced land degradation have been conducted in countries where salinity is a major problem, notably Australia, India, the United States, Iraq, Pakistan, Kazakhstan, Uzbekistan and Spain. Salinity-related economic analyzes particularly have a long history in Australia, where salinity is a prominent problem.

Studies on economic costs of salinization attributable to climate change are limited. One exception is PESETA (Projection of Economic impacts of climate change in Sectors of the European Union based on boTtom-up Analysis) a major EU-funded project on the impacts of climate change in Europe covering 25 countries (Richards and Nicholls 2009; Bosello et al. 2012). This study examined the direct biophysical impacts of climate change and sea-level rise on: (i) increased erosion, (ii) increased flood risk and inundation, (iii) coastal wetland loss and change and (iv) (surface) salinization costs. The higher order costs of these impacts were then assessed using a computable general equilibrium (CGE) modelling framework with country-level detail to assess the wider economic implications. Focusing on the salinization part of the study, the results show that salinity intrusion costs range from $€ 577$ to 610 million per year and are projected to significantly increase with sea-level rise and over time across all scenarios investigated in the study. The study further notes that adaptation is crucial to keep the negative impacts of sea-level rise at an "acceptable" level.

\subsection{METHODOLOGICAL FRAMEWORK TO ASSESSING ECONOMIC IMPACT OF SALINIZATION}

\subsubsection{Overall Approach and Conceptual Framework}

The impacts of salinization on agriculture depend on a wide range of related factors. This includes the type of salinization (the process that causes salinization), the 


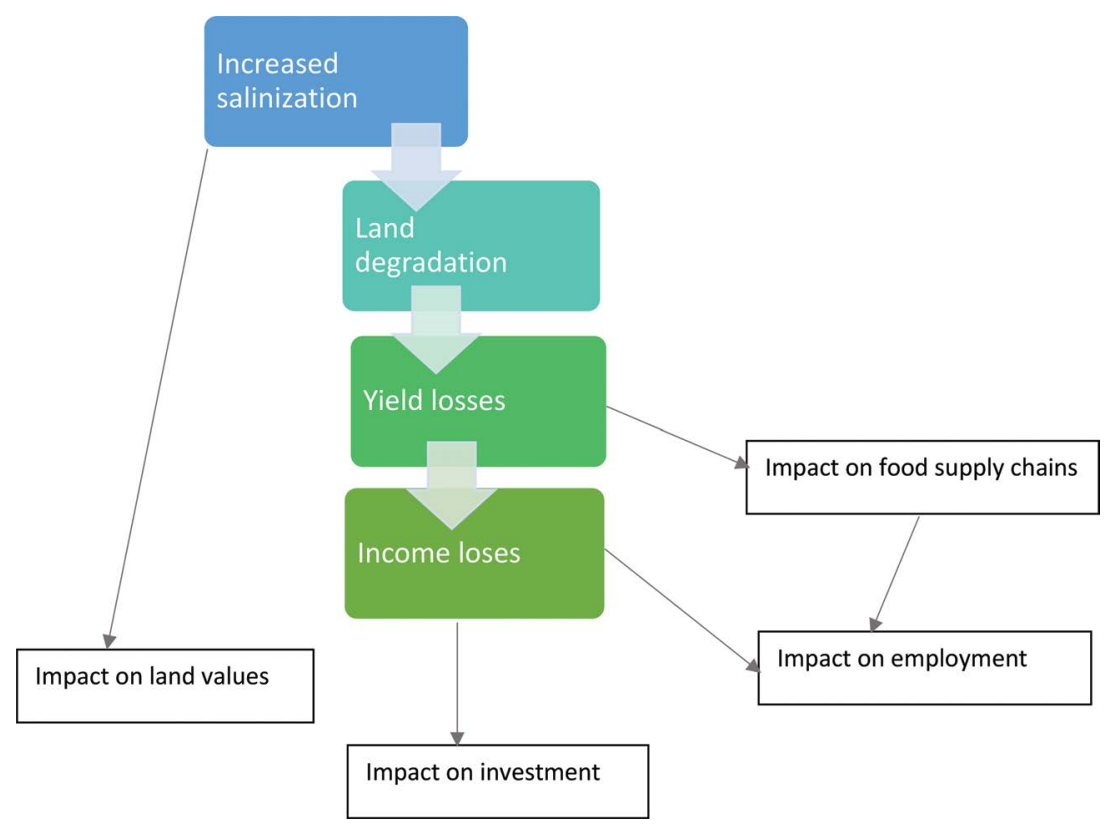

FIGURE 6.1 Stylized framework for assessing farm scale and wider impact of salinization.

degree of salinization (the present state of salinization), the types of crops grown in the affected region, the value of those crops, shocks (such as climate change induced sea-level rise) and any farm-level decisions to ameliorate the impacts of salinization (which may include the planting of salt-tolerant crops).

This section develops a modelling framework that attempts to incorporate these variables to allow farm-level and wider level evaluations of the economic risks of soil salinization. The chain of causes and effects that must be appraised is represented diagrammatically in Figure 6.1. As depicted in the figure, the economic analysis focuses on the scale of impact along each bold arrow. The wider economic impacts can also be estimated at the regional levels by using appropriate multipliers and other local evidence.

To operationalize the framework, we employed multistage empirical modelling and scenario analysis to represent the chain of causes and effects of salinization on crop yields and "downstream" economic impacts at the farm and regional or wider scales. As alluded to earlier, these impacts critically depend on the type and degree of salinization, among other factors. In our approach, the type of salinization follows a typology identified by De Waegemaeker (2019) i.e. irrigation, seepage, flood salinization and aerosol (or airborne) salinization. However, we do not include aerosol salinization in our analyzes partly because of the unavailability of data on the impact or significance of this type of salinization in our study area. The degree of salinization was developed from detailed scenario analysis informed by a critical review of the literature and analysis of data from a survey of partners in Interreg VB North Sea Region SalFar project, a project co-funded by Interreg VB North Sea Region Programme. 


\section{TABLE 6.2}

\section{A Summary of Methodology and Data Sources Used to Assess Economic Impacts of Salinization}

\section{Farm Scale Impacts}

Step 1: Develop a typology of salinization based on salinization processes identified in De Waegemaeker (2019) i.e. irrigation, seepage and flood salinization.

Step 2: For each type of salinization process, develop a range of salinity scenarios informed by a critical review of the literature (e.g. van Straten et al. 2019) and data from a survey of SalFar project partners.

Step 3: Collate a representative list of crops grown in the North Sea Region using information from the survey of SalFar project partners.

Step 4: Conduct a yield gap analysis to estimate production penalties (relative yield) of specific crops under each type of salinization process and salinity scenarios, using crop salt tolerance parameters provided by Salt Farm Texel (de Vos et al. 2016).

Step 5: Estimate the yield loss (tons/ha) of specific crops under each type of salinization process and salinity scenarios, using EUROSTAT (https://ec.europa.eu/eurostat) country-level data (2019) on average yield per ha for each crop.

Step 6: Based on the estimated yield gaps per ha, calculate the gross value of production attributable to the estimated yield gaps, under each type of salinization process and salinity scenarios, using EUROSTAT (https://ec.europa.eu/eurostat) data (2019) on average prices of specific crops.

\section{Regional/Economy-wide Scale Impacts}

Step 7: Estimate the area affected or at risk of each type of salinization process, using GIS mapping of areas at risk (where available) or expert opinion, combined with typical crop composition using satellite remote sensing data, where available.

Step 8: Extrapolate crop yield loss to areas at risk of salinity under each type of salinization process, using EUROSTAT (https://ec.europa.eu/eurostat) data (2019) on average yield per ha for the regionally representative crop composition.

Step 9: Estimate expected financial losses, extrapolated to areas affected or at risk of salinization, under each type of salinization process, using EUROSTAT (https://ec.europa.eu/eurostat) data (2019) on average prices of the regionally representative crop composition.

Step 10: Scale up output losses to calculate impacts to the wider economy, using appropriate multipliers where data are available.

Our approach encompasses a series of logical steps, bringing together data from several sources as summarized in Table 6.2.

\subsubsection{Salinity Processes and Scenarios}

Salinity measurement is based on the electrical conductivity of the soil saturation extract $\left(\mathrm{EC}_{\mathrm{e}}\right)$ in deciSiemens per meter $(\mathrm{dS} / \mathrm{m})$ and chloride concentrations (de Vos et al. 2016). The soil is considered saline when the ECe is $4 \mathrm{dS} / \mathrm{m}$ or higher (Table 6.3). Depending on the level, salinity may have a profound influence on plant productivity, as shown in the table below and described in detail in de Vos et al. (2016).

To facilitate comparability and compatibility, we employed a typology of salinization developed by De Waegemaeker (2019) as a basis of our economic analysis: irrigation salinization, flood salinization and seepage salinization and aerosol salinization. 
TABLE 6.3

Soil Salinity Classes and Effect on Crop Growth

$\begin{array}{lcl}\text { Soil Salinity Class } & \text { Salinity }\left(\mathbf{E C}_{\mathbf{e}} \text { in } \mathbf{~} \mathbf{S} / \mathbf{m}\right) & \text { Effect on Plants } \\ \text { Non saline } & 0-2 & \text { Salinity effects negligible } \\ \text { Slightly saline } & 2-4 & \text { Yields of sensitive crops may be restricted } \\ \text { Moderately saline } & 4-8 & \text { Yields of many crops are restricted } \\ \text { Strongly saline } & 8-16 & \text { Only tolerant crops yield Satisfactorily } \\ \text { Very strongly saline } & >16 & \text { Only a few very tolerant crops yield satisfactorily }\end{array}$

Source: Adapted from Van Orshoven et al. (2012).

It may be noted that this typology categorizes the processes that create saline soil conditions and not the resulting saline soil conditions. Due to the unavailability of data on the actual degree of salinity, we use scenario analysis to estimate the potential economic impact of salinization. To calibrate the analysis of economic impacts, we developed a range of salinity scenarios, from slightly saline to strongly saline. This was informed by a critical review of the literature (e.g. van Straten et al. 2019) and data from a survey of SalFar project partners. Table 6.4 summarizes salinity scenarios used in the analysis.

For irrigation salinization, we used four different salinity levels of irrigation water. The salinity levels of irrigation water were chosen based on the study by Van Straten et al. (2019).

For seepage salinization we used two groundwater salinity scenarios. The calibration of the levels of groundwater salinity scenarios was based on data on actual salinity of groundwater obtained from the province of Groningen (measured as chloride $(\mathrm{Cl})$ concentrations). Looking at the $\mathrm{Cl}$ groundwater concentrations across the province of Groningen we chose the concentrations corresponding to four percentiles

\section{TABLE 6.4}

\section{Salinity Scenarios Employed in Economic Analysis}

$\begin{array}{ll}\text { Salinization Process } & \begin{array}{l}\text { Description } \\ \text { Irrigation salinization (IS) }\end{array} \\ & \begin{array}{l}\text { Salinization that results from irrigation of } \\ \text { non-saline agricultural soils with salt or } \\ \text { brackish water. }\end{array} \\ \text { Seepage salinization (SS) } & \begin{array}{l}\text { Salinization that results from the rise of salt } \\ \text { rich groundwater. The salt rich groundwater } \\ \text { may be hydrologically linked to nearby } \\ \text { seawater. }\end{array} \\ \text { Flood salinization (FS) } & \begin{array}{l}\text { Salinization that occurs as soils are flooded by } \\ \text { brackish or salt-rich water. Flood risk may be } \\ \text { exacerbated by climate change }\end{array}\end{array}$

Salinity Scenario Levels ( $\mathrm{EC}_{\mathrm{w}}$ in $\left.\mathrm{dS} / \mathrm{m}\right)$

4, 8, 12, 16

$0.02,0.09,0.2,0.7$

$7.1,6.08,5.06,3.03,4.04$ 
$0 \%, 25 \%, 50 \%$ and $75 \%$ (corresponding to $6,26,64$ and $215 \mathrm{mg} / \mathrm{l}$ respectively) of the $\mathrm{Cl}$ distribution (or $\mathrm{ECw}$ values of $0.02,0.09,0.2,0.7 \mathrm{dS} / \mathrm{m}$ equivalent). However, in the empirical analysis, we focused only on the salinity scenario levels that had a significant impact on yields (i.e. $215 \mathrm{mg} / \mathrm{L}$ ). The result of the other salinity levels had only a marginal or no impact on crop yield.

Finally, for flood salinization, we considered that seawater flooding impacts on yield can occur over many years. Therefore, to assess total yield loss (current and future years) as the soil recovers, we firstly calculated the response of different crop types (relative yields) to salt-affected land. We did this by predicting salt soil levels in recovery years. However, for farm-scale assessments, this method could be adapted by basing on known, or historic salt levels. We assumed the complete loss of the standing crop during the flood (zero yield in flood year) followed by a "sliding" recovery approach during the following years, where the rate of recovery was a function of the salt tolerance per crop type based on predicted salt soil levels. Thus, the model considered that highly tolerant crops recover yield on inundated fields at a faster rate than sensitive crops. Salt recovery time depends on soil type; for example, a well-drained sandy soil may recover back to post-flood production in 2 years, whereas a heavier, poorly drained soil may take up to 7 years. As such, without knowledge of site specific drainage regimes, we modelled six recovery scenarios on a scale of 2-7 year soil recovery.

To evaluate the impact of soil salinity and facilitate comparisons, where appropriate, we converted irrigation water salinity (i.e. electrical conductivity of irrigation water, $\mathrm{EC}_{\mathrm{w}}$ ) into corresponding soil salinity $\left(\mathrm{EC}_{\mathrm{e}}\right)$ using procedures developed in Ayers and Westcot (1985) and Grattan (2002). Where soil salinity was measured in chloride, we converted soil salinity in chloride concentrations ( $\mathrm{mg} / \mathrm{l}$ ) into equivalent EC (in ds $/ \mathrm{m}$ ) measurements, using established correlations in the literature (e.g. de Vos et al. 2016).

\subsubsection{Economic Model: Impact of Salinity on Crop Yield and Output}

Crop salt tolerance can be measured on the basis of two parameters: (a) the threshold salinity that is expected to cause the initial significant reduction in the maximum expected yield and (b) the percentage of yield expected to be reduced for each unit of added salinity above the threshold value (i.e. slope) (Shannon and Grieve 1998). Using these parameters, the first step in economic analysis was to estimate the crop relative yields based on the following model (Maas and Hoffman 1977; Tanji and Kielen 2002):

$$
Y r=100-b(E C e-a)
$$

where $\mathrm{Yr}$ is the relative crop yield relative to the potential (under no salinity); $a$ is the crop salinity threshold in $\mathrm{dS} / \mathrm{m} ; b$ is the slope expressed in percent per $\mathrm{dS} / \mathrm{m}$; and $E C e$ is the predicted (or measured) salinity level (dS/m) of the soil. Values for $a$ and $b$ for each crop are traditionally based on FAO salt tolerance data which cover a comprehensive list of crops, albeit rather dated and were based on experiments mainly conducted in non-temperate environments (Maas and Hoffman 1977; Tanji 
and Kielen 2002). However, in our analysis we used an updated set of parameters provided in de Vos et al. (2016) which were derived from experiments in Europe (Salt Farm Texel), albeit covering a limited range of crops. Finally in our analysis, values for $E C e$ were based on soil salinity scenarios discussed in the previous section (Table 6.4).

To assess impacts to yields and crop tonnage, reference data for yield per hectare were obtained from EUROSTAT for the year 2019 (https://ec.europa.eu/eurostat). The total tonnage lost of each crop in each year was calculated using the following formula:

$$
L Y_{x}=\left(\mathrm{h} \times Y_{F M}\right) \times\left(\frac{100-Y r_{x}}{100}\right)
$$

where $L Y_{x}$ is the loss in yield (tons); $h$ is the hectare coverage of each crop; $Y_{F M}$ is the yield per hectare values for each crop; and $Y r_{x}$ is the relative yield, based on the salinity and crop tolerance derived in equation 6.1. These were converted to financial losses using data for prices per ton of each crop obtained from EUROSTAT (https://ec.europa.eu/eurostat). Crops were chosen based on a review of economic importance of various crops in Europe, information on the most commonly grown crops in the North Sea Region of Europe and information from the survey of SalFar project partners. A refined list of crops for analysis included potato ${ }^{1}$, barley, sugar beet, wheat, maize, ryegrass, carrot, onion, lettuce and cabbage.

Finally, the farm-level impacts (yield and financial losses) were scaled up to a wider (regional) level, where data were available. This depended on the availability of reliable data on the extent and severity of salinization (or areas at risk of salinization) as well as detailed data on crop composition and distribution.

\subsection{RESULTS AND DISCUSSION: ECONOMIC IMPACTS OF SALINIZATION}

Economic impacts of salinity can be assessed at different scales or levels: farm, regional and economy-wide scales. We begin with farm-level impacts by estimating relative (and absolute) yield and financial losses of specific crops under different salinization processes and salinity scenarios.

The analysis will show the potential economic impact of different salinization processes on crop yields. This can inform an assessment of crops that would be more affected by soil salinity and the countries that would undergo larger financial losses depending on the economic importance of the crops grown. We then extrapolate the impacts to the regional level (i.e. beyond the farm level), illustrated with case studies across the North Sea Region.

\subsubsection{Farm-Level Economic Impacts of Salinization}

\subsubsection{Impacts of Irrigation Salinization}

To assess the impact of irrigation salinization, we estimated the relative yields of key crops under a range of salinity levels and crop salt tolerance parameters 


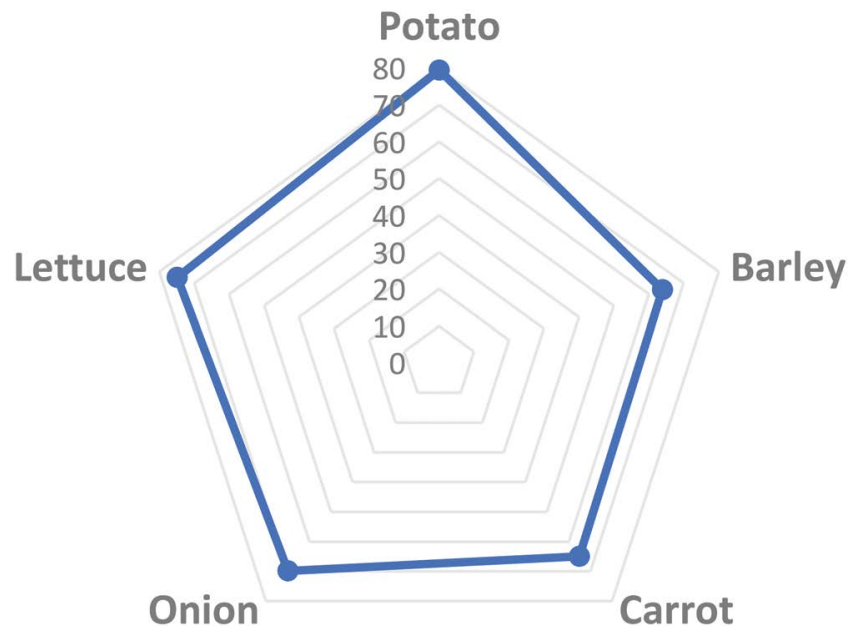

FIGURE 6.2 Relative yield of key crops under irrigation salinity.

given in de Vos et al. (2016). To represent the range of salinity impacts, we present the results of saline irrigation water of $\mathrm{EC}_{\mathrm{w}} 4 \mathrm{dS} / \mathrm{m}$. Relative yields range from $64 \%$ (barley) to $80 \%$ (potatoes), indicating potatoes are comparatively more salt-tolerant and barley is the least salt-tolerant (Figure 6.2).

In relation to yield and financial losses, we used the salinity effects on potato and barley as an example and compared yield and financial penalties across the North Sea Region countries (Figure 6.3). For instance, if potato was irrigated with $\mathrm{EC}_{\mathrm{w}} 4 \mathrm{dS} / \mathrm{m}$,

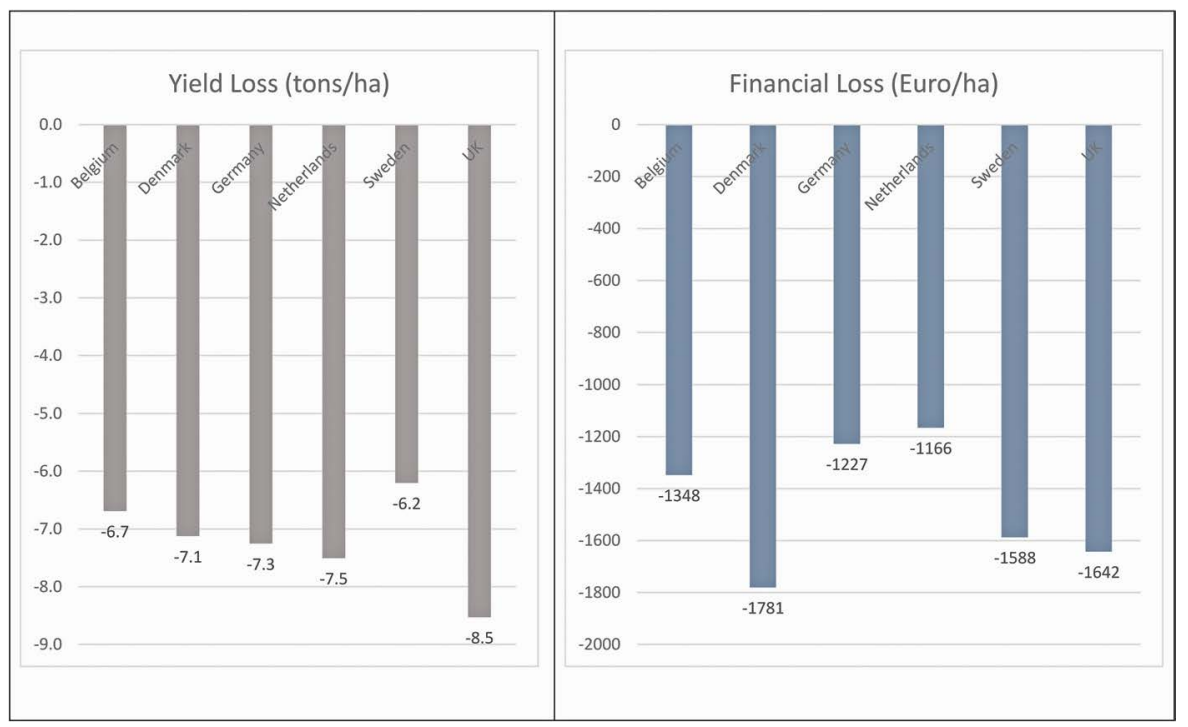

FIGURE 6.3 Irrigation salinization: Yield and financial losses of potato. 


\begin{tabular}{lcc}
$\begin{array}{l}\text { TABLE 6.5 } \\
\text { Irrigation Salinization: Yield and Financial Losses of Barley } \\
\text { across Countries }\end{array}$ & \\
& & \\
Country & Yield Loss (tons/ha) & Financial Loss (€/ha) \\
Belgium & 2.8 & 391.67 \\
Denmark & 1.6 & 230.72 \\
Germany & 2.1 & 416.00 \\
Netherlands & 2.5 & 483.60 \\
Sweden & 1.1 & 141.00 \\
United Kingdom & 2.0 & 240.55 \\
Norway & 1.4 & - \\
\hline
\end{tabular}

the yield losses ranged from 6.2 tons/ha (Sweden) to 8.3 tons/ha (the United Kingdom). We then converted these yield losses into financial penalties using crop price data from EUROSTAT (https://ec.europa.eu/eurostat).

The results ranged from $€ 1478$ to $€ 2259$; Denmark incurred the highest financial loss followed by the UK, while the Netherlands would be the least financially affected but would incur the second largest yield loss per ha after the UK. For Norway, prices were not available in EUROSTAT, hence we could only say that it would incur the least potential yield losses per ha. Similarly, comparing the financial losses under the other three irrigation levels across the countries, Denmark followed by the UK were the most affected by potato yield losses.

Estimating the impact of irrigation salinity (EC $4 \mathrm{dS} / \mathrm{m}$ ) on barley showed yield penalties ranging from 1.1 tons/ha (Sweden) to 2.8 tons/ha (Belgium) with financial losses ranging from $€ 141 /$ ha (Sweden) to $€ 483.60 /$ ha (Netherlands). The results are summarized in Table 6.5. Belgium followed by the Netherlands, would undergo the highest yield losses among the countries, while the largest financial losses would occur in the Netherlands.

\subsubsection{Impacts of Seepage Salinization}

To assess the impact of seepage salinization, we used salinity (chloride concentration of $215 \mathrm{mg} / \mathrm{L}$ ) scenarios of groundwater, assuming that groundwater reaches the root zone of the crops. However, the results show that all salinity scenarios would have no significant impact on the yield of all the crops investigated as shown in Table $6.6^{2}$. Further investigation using FAO salinity tolerance data shows that the only crops that would be affected are carrot and onion. For this type of salinization, we were not able to estimate potential yield and financial losses for each country for carrot and onion because EUROSTAT does not provide data for the prices and yields of vegetables.

\subsubsection{Impacts of Flood Salinization}

In the case of flood salinization, we estimated the relative yields and potential yield losses assuming a flooding event. Following Gould et al. (2020), we assumed the complete loss of the standing crop during the flood followed by a sliding recovery approach during the following years, where the rate of recovery was a function of the salt tolerance per crop type based on predicted salt soil levels. 


\section{TABLE 6.6}

\section{Seepage Salinization: Relative Yields for All Crops}

$\begin{array}{lcc} & \begin{array}{c}\text { Relative Yield (\%) } \\ \text { Crops }\end{array} & \begin{array}{c}\text { Relative Yield (\%) } \\ \text { (Based on Texel Salt Farm Salinity Tolerance } \\ \text { Parameters (de Vos et al. 2016)) }\end{array} \\ \text { Potato } & 100 & \begin{array}{c}\text { Parameters } \\ \text { (Tanji and Kielen 2002)) }\end{array} \\ \text { Barley } & 100 & 100 \\ \text { Sugar beet } & * & 100 \\ \text { Wheat } & * & 100 \\ \text { Maize } & * & 100 \\ \text { Ryegrass } & * & 100 \\ \text { Carrot } & 100 & 100 \\ \text { Onion } & 100 & 95.83 \\ \text { Lettuce } & 100 & 98.44 \\ \text { Cabbage } & 100 & 100 \\ & & 100\end{array}$

* Texel Salt Farm salinity tolerance parameters (de Vos et al. 2016) were unavailable for these crops.

Hence, in the first year after the flood, we assumed zero yields while in the second recovery year we assumed soil salinity with an $\mathrm{EC}_{\mathrm{e}}$ of $7.1 \mathrm{dS} / \mathrm{m}$, a typical post-flood salinity level recorded in previous saline flooding research in the UK North Sea coastal systems (Hazelden and Boorman 2001; Gould et al. 2020). Taking as an example potato yields grown in the second recovery year after a potential flood, we compared the results across the North Sea Region countries. As shown in Figure 6.4, yield losses for potato ranged from 7.86 tons/ha (Sweden) to 10.81 tons/ha (UK) while financial losses ranged from $€ 1,478 /$ ha (Netherlands) to $€ 2,259 /$ ha (Denmark). Similar to the case of irrigation salinization, results showed that Denmark would incur the largest financial losses if potato was grown in a field 2 years after a flood event and the UK would incur the highest yield losses per ha.

Results for barley (Table 6.7), showed that Belgium would incur the highest yield losses per ha, losing $460.05 € /$ ton and the Netherlands would lose $608.4 € / t$. Comparing potato and barley financial losses per ton, it is apparent that countries or/ and regions where potato is the principal crop would undergo more severe financial losses in a case of flooding than areas which primarily grow barley.

\subsubsection{Regional Economic Impact of Salinization}

In this section, we scale up salinity impacts to the wider (regional) level, focusing on selected case study areas in the North Sea Region of Europe, where data were available. We present three case studies on regional economic impact of the main types of salinization: (a) irrigation salinization-Netherlands (Groningen) (b) seepage salinization-Belgium (Oudlandpolder) and (c) flood salinization-UK (Lincolnshire). 


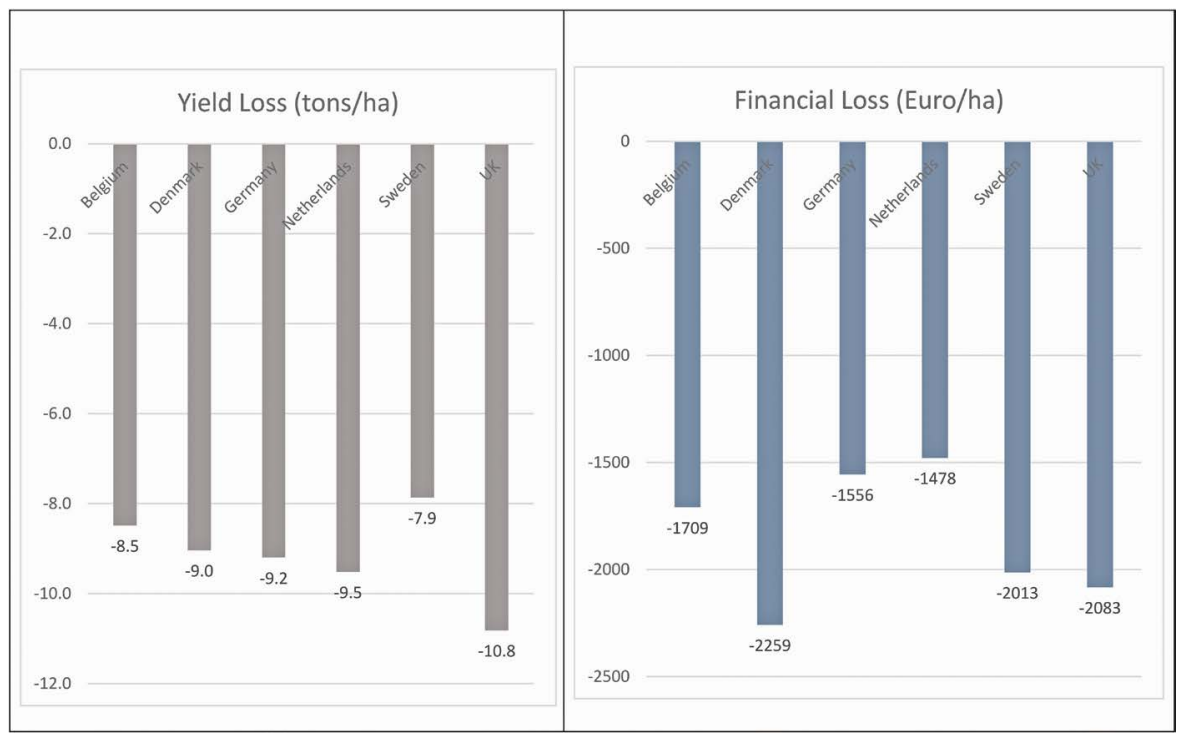

FIGURE 6.4 Yield and financial losses for potato under flood salinization across all countries.

Although the potential for salinization is geographically extensive, and not localized to any one region along the North Sea coastline, we focused on the three case studies in our empirical analysis partly because of limited availability of data on salinity risks in the region and because of anecdotal evidence of significant risks of salinization in these case study areas. For example, coastal flooding risks (and associated salinity risks) are significant within Greater Lincolnshire (UK), a lowlying, highly productive agricultural land with a history of flooding, including as recently as the year 2013. It is in this vein that the case of regional economic impact of flood salinization is based on a recent study conducted by Gould et al. (2020) on the impact of coastal flooding on agriculture in Lincolnshire, UK.

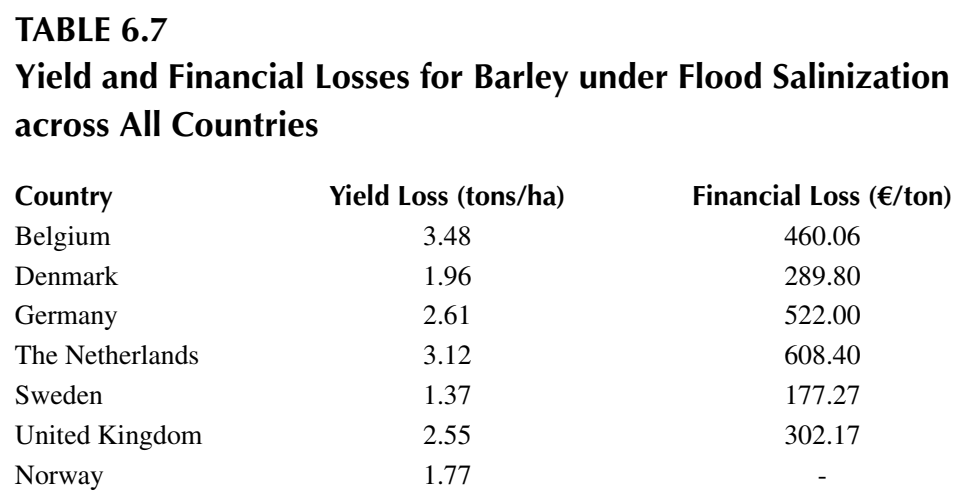




\subsubsection{Case Studies from Europe's North Sea Region}

Table 6.8 presents the results of an analysis of a regional economic impact of the main types of salinization for the three case studies: irrigation salinization-Netherlands (Groningen), seepage salinization-Belgium (Oudlandpolder) and flood salinization-UK (Lincolnshire).

Though not strictly comparable, the results suggest that flood salinization potentially has the greatest economic impact (as indicated by the financial loss per ha), followed by seepage salinization and irrigation salinization in that order. It should be noted, however, that these losses are limited to direct farm impact in terms of yield losses, i.e. these exclude the wider economy "multiplier" or supply chain costs that can be substantial. For example, as will be discussed in more detail in the case of flood salinization in Lincolnshire (UK) in the next section, these wider economy impacts amount to approximately $€ 115$ million in GVA (Gross Value Added) losses.

\subsubsection{Regional Impact of Flood Salinization: Lincolnshire, UK}

To represent the case studies on the regional economic impact of salinization, this section presents a more detailed analysis of the potential impact of flood salinization

TABLE 6.8

\section{Regional Economic Impact of Salinization: North Sea Region Case Studies}

\begin{tabular}{|c|c|c|c|c|c|c|}
\hline $\begin{array}{l}\text { Salinization } \\
\text { Process }\end{array}$ & Case Study & $\begin{array}{c}\text { Area at } \\
\text { Risk } \\
\text { (ha) }\end{array}$ & Methods & $\begin{array}{c}\text { Estimated } \\
\text { Loss in } \\
\text { Yield } \\
\text { (tons) }\end{array}$ & $\begin{array}{c}\text { Estimated } \\
\text { Financial } \\
\text { Loss (Euro) }\end{array}$ & $\begin{array}{c}\text { Financial } \\
\text { Loss per } \\
\text { ha (Euro/ } \\
\text { ha) }\end{array}$ \\
\hline $\begin{array}{l}\text { Irrigation } \\
\text { salinization }\end{array}$ & $\begin{array}{l}\text { Holland } \\
\text { (Groningen) }\end{array}$ & 17,526 & $\begin{array}{l}\text { GIS mapping of affected } \\
\text { areas and analysis of } \\
\text { regionally representative } \\
\text { cropping composition } \\
\text { and distribution. } \\
\text { Groundwater salinity } \\
\text { data }(\mathrm{Cl}) \text { provided by the } \\
\text { Province of Groningen }\end{array}$ & 147,992 & $34,947,861$ & $1,994.06$ \\
\hline $\begin{array}{l}\text { Seepage } \\
\text { salinization }\end{array}$ & $\begin{array}{l}\text { Belgium } \\
\text { (Oudlandpolder) }\end{array}$ & 11,938 & $\begin{array}{l}\text { Mapping of affected areas } \\
\text { and analysis of regionally } \\
\text { representative cropping } \\
\text { composition and } \\
\text { distribution. Groundwater } \\
\text { salinity data (EC) } \\
\text { provided by Belgium }\end{array}$ & 147,663 & $27,381,670$ & $2,293.66$ \\
\hline $\begin{array}{l}\text { Flood } \\
\text { salinization }\end{array}$ & $\begin{array}{l}\text { UK } \\
\text { (Lincolnshire) }\end{array}$ & 108,238 & $\begin{array}{l}\text { Climate (flood modelling) } \\
\text { and salinization impact } \\
\text { mapping based on GIS } \\
\text { and satellite data } \\
\text { analysis of cropping } \\
\text { composition. }\end{array}$ & 2,022,385 & $279,548,899$ & $2,582.72$ \\
\hline
\end{tabular}


in Lincolnshire, UK, a region where coastal flooding presents a significant risk to agriculture. Again, the results presented here are based on recent research on the impact of coastal flooding on agriculture in Lincolnshire, UK conducted by Gould et al. (2020). In the study, economic and yield losses were estimated based on a combination of predicted flood models, typical crop composition using satellite remote sensing data and soil type/drainage potential of a flood event for a given coastal region. In particular, the study defined three flood scenarios reflecting: (i) current breach risk, (ii) future breach risk and (iii) a "big" flood event (see Gould et al. 2020 for details).

The primary focus of this chapter, however, is on the current breach risk. For all breaches, we assumed that the post-breach regime was to repair the breach and continue the existing defence strategy. To assess current areas exposed to sea bank breach risk, we used breach scenarios obtained from the UK Environment Agency. These flood scenarios are used to inform the UK flood defence strategy. They modelled the ingress of flood water for a 1 in 200 years breach ( 72 hours duration) of sea defences under 2006 climate conditions. These are the most recent breach scenarios data released by the Environment Agency, and as such we describe these as "current." We used breach scenarios from 67 individual locations spanning a $105 \mathrm{~km}$ stretch of the Lincolnshire coastline (Figure 6.5). To account for localized differences in tidal behaviour, we grouped these 67 model scenarios into four Coastal Zones (CZs) as shown in Figure 6.5. Using the Land Cover Plus data, average crop composition per breach area

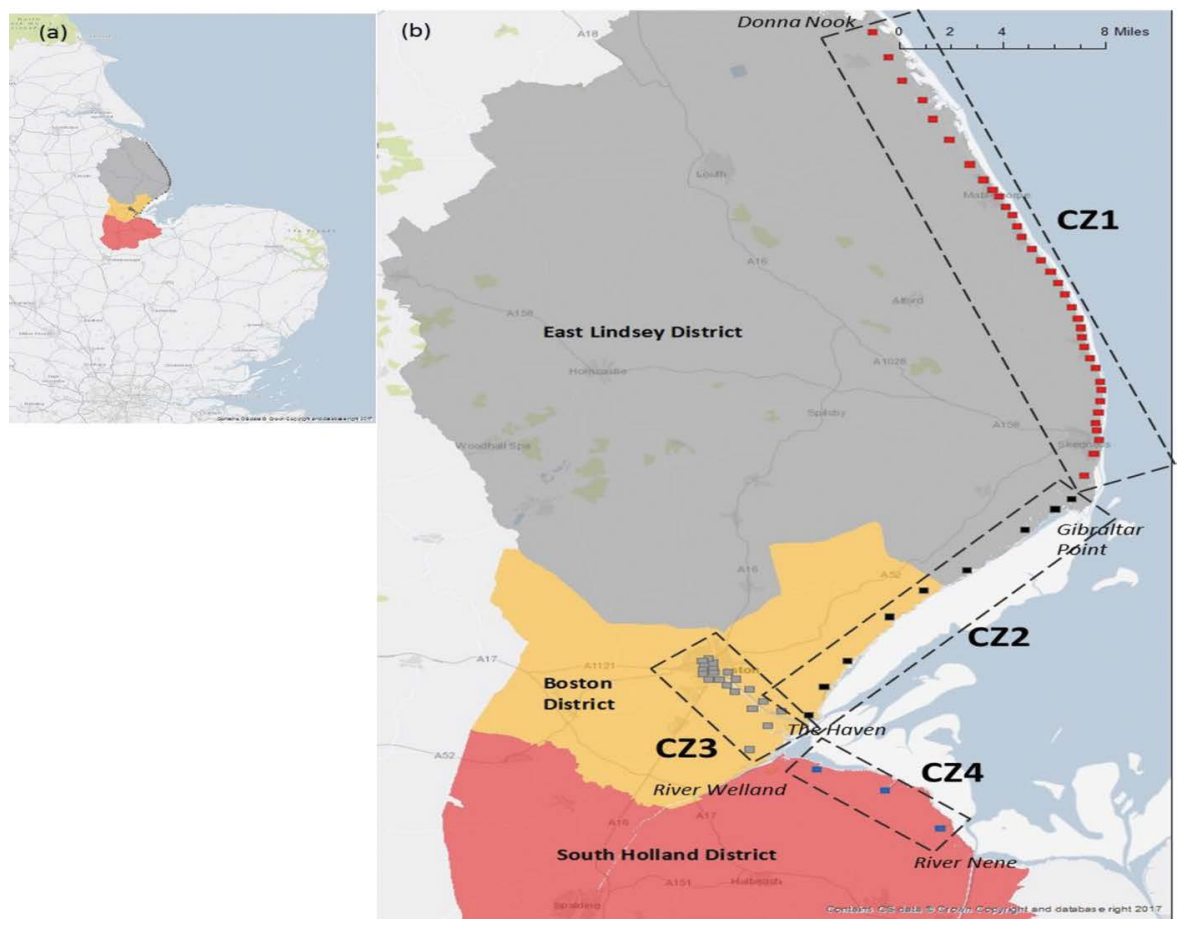

FIGURE 6.5 Location of the case study area and location of each analyzed breach scenario. 
was calculated for each of the four CZs, giving a typical breach crop composition for each stretch of coastline.

To assess total yield loss (current and future years) as the soil recovers, we firstly calculated the response of different crop types (relative yields) to salt-affected land. In this chapter, we did this by predicting salt soil levels in recovery years. However, for farm-scale assessments, this method could be adapted based on known or historic salt levels. We assumed the complete loss of the standing crop during the flood (zero yield in flood year) followed by a sliding recovery approach during the following years, where the rate of recovery was defined as a function of the salt tolerance per crop type based on predicted salt soil levels. Thus, the modelling approach captured the fact that highly tolerant crops would recover yield on inundated fields at a faster rate than sensitive crops.

To assess impact, reference data for yield per hectare were obtained from the John Nix Farm Management Pocketbook (Redman 2016), an information source for financial assessments of UK farmland. These were readily converted into output losses in monetary terms using crop price data obtained from EUROSTAT.

Figure 6.6 diagrammatically shows the yield and financial losses, aggregated across all the coastal zones over the full soil recovery time for all 1-7 years salt recovery time scenarios (1-7 years). Total yield losses over the recovery period were estimated to be up to 418,866 tons while the output losses per ha averaged $£ 5,636$ over the recovery period.

To investigate heterogeneity in yield and output losses across CZs, we turn to disaggregated analysis of impacts. Figure 6.7 displays the total yield losses (tons) across CZs. The results reveal a spatial heterogeneity in yield recoveries and hence yield losses across regions $(\mathrm{CZs})$ due to differences in salt tolerance and crop composition across zones. $\mathrm{CZs}$, where salt sensitive crops are dominant, would be worst hit by flood salinization. For example, it was found that $\mathrm{CZs}$, where salt sensitive crops are dominant, suffered a

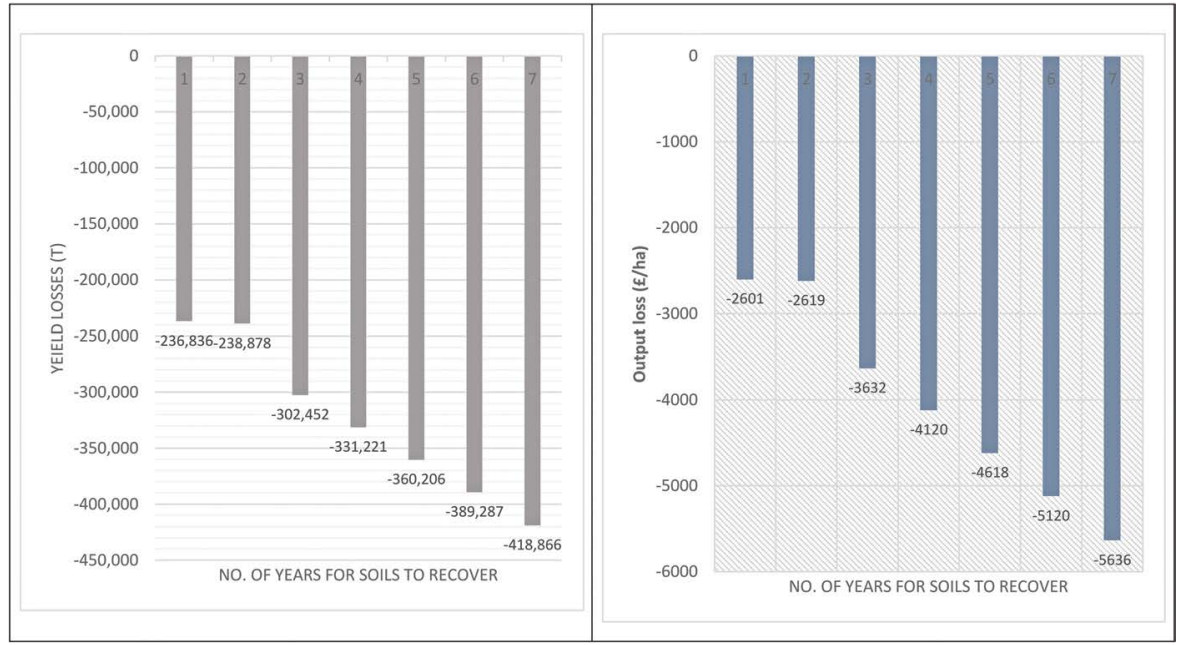

FIGURE 6.6 Regional economic impact of flood salinization: total yield and output losses per ha over full soil recovery time for all $1-7$ years salt recovery time scenarios in Lincolnshire, UK. 


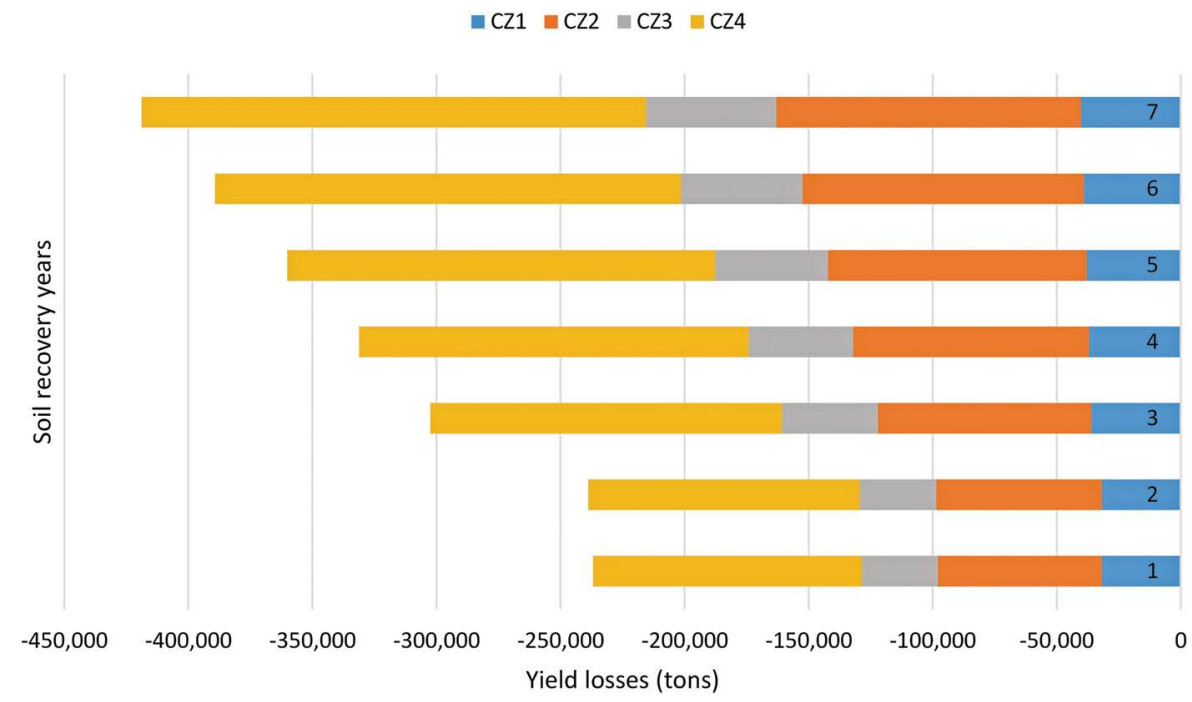

FIGURE 6.7 Regional economic impact of flood salinization; total yield losses across coastal zones in Lincolnshire, UK.

$88 \%$ yield loss compared to a $27 \%$ yield loss in more "tolerant" CZs. This implies greater potential for salt-tolerant crops in these areas, particularly in early recovery phases as a remediation or adaptation option for salt degraded land.

Table 6.9 reports the total yield losses, output losses and output losses per ha over the full soil recovery time for all 1-7 years salt recovery time scenarios (1-7 years) for each coastal zone. This is based on the average breach crop composition in each coastal zone (CZ1-CZ4). The results show that in the first (flood) year alone, a single breach could deprive farms of a total yield of 31,778 tons in CZ1, 66,051 tons in CZ2, 30,671 tons in CZ3 and 108,336 tons in CZ4. When yield losses were converted into potential losses in monetary terms, this translated to $£ 2,684,625$ per breach in CZ1, $£ 9,608,181$ in CZ2, $£ 4,183,383$ in CZ3 and $£ 15,264,116$ in CZ4.

The results in Table 6.9 further show a non-linear yield recovery (i.e. differences in yield and output losses between years are not uniform) which may be related to the salt tolerance of the typical crop composition. Within 2-3 years, beet, wheat, grass and barley will return to $100 \%$ yields, whilst yield losses will remain in potatoes and vegetables for longer. As such, in the earlier recovery years (e.g. years 2-3) of CZs dominated with more salt-tolerant crops, gains in yield recovery may appear to be more rapid than in later years. This is true for $\mathrm{CZ1}$, where the greatest yield losses were for more salt-tolerant crops, whereas in the other three zones, the greatest losses were for more salt sensitive crops.

The more salt sensitive crops typical of our study region tend to have higher commercial value. Such crops suffer more damage and have greater financial loss, exacerbating the financial flood impact. When total output losses were converted to pounds sterling per hectare of agricultural land flooded (over the entire recovery duration), the highest values were found in CZ2 ( $£ 3,257$ to $£ 7,510$ per ha), followed by CZ4 ( 2,912 to $£ 6,533$ per ha), then CZ3 ( $£ 2,867$ to $£ 6,380$ per ha), with CZ1 having the lowest ( $£ 1,368$ to $£ 2,119$ ). 


\section{TABLE 6.9}

Total Yield Losses, Output Losses and Output Losses per ha over Full Soil Recovery Time for All 1-7 Years Salt Recovery Time Scenarios (1-7 years)

\begin{tabular}{|c|c|c|c|c|c|c|c|c|}
\hline & & \multirow[b]{2}{*}{ Flood Year } & \\
\hline & & & 2 & 3 & 4 & 5 & 6 & 7 \\
\hline \multirow{4}{*}{ 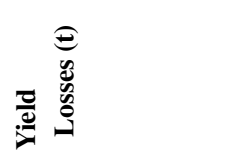 } & CZ1 & 31,778 & 31,825 & 36,095 & 36,959 & 37,863 & 38,985 & 40,225 \\
\hline & $\mathrm{CZ2}$ & 66,051 & 66,659 & 85,991 & 95,112 & 104,271 & 113,442 & 122,702 \\
\hline & $\mathrm{CZ3}$ & 30,671 & 30,879 & 38,691 & 42,109 & 45,550 & 49,041 & 52,589 \\
\hline & CZ4 & 108,336 & 109,515 & 141,675 & 157,041 & 172,522 & 187,819 & 203,350 \\
\hline \multirow{4}{*}{ 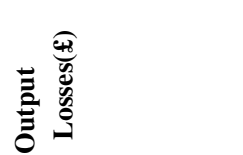 } & CZ1 & $2,684,625$ & $2,689,932$ & $3,236,549$ & $3,458,680$ & $3,690,058$ & $3,916,679$ & $4,158,767$ \\
\hline & $\mathrm{CZ2}$ & $9,608,181$ & $9,680,736$ & $13,823,189$ & $15,853,098$ & $17,921,588$ & $20,013,414$ & $22,150,743$ \\
\hline & $\mathrm{CZ3}$ & $4,183,383$ & $4,209,929$ & $5,919,917$ & $6,746,154$ & $7,589,012$ & $8,439,952$ & $9,311,382$ \\
\hline & $\mathrm{CZ4}$ & $15,264,116$ & $15,409,027$ & $21,675,166$ & $24,737,134$ & $27,865,800$ & $31,013,861$ & $34,246,798$ \\
\hline \multirow{4}{*}{ 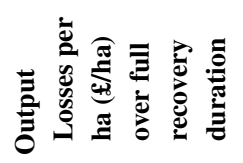 } & CZ1 & 1,368 & 1,371 & 1,650 & 1,763 & 1,881 & 1,996 & 2,120 \\
\hline & $\mathrm{CZ2}$ & 3,257 & 3,282 & 4,687 & 5,375 & 6,076 & 6,785 & 7,510 \\
\hline & $\mathrm{CZ3}$ & 2,867 & 2,885 & 4,057 & 4,623 & 5,200 & 5,783 & 6,380 \\
\hline & $\mathrm{CZ4}$ & 2,912 & 2,940 & 4,135 & 4,719 & 5,316 & 5,917 & 6,533 \\
\hline
\end{tabular}


This suggests CZ1, where grazing is more commonplace and there is less vegetable and potato production, is a more resilient coastal zone to the long term impacts of flooding.

Finally, we turn to the impacts of coastal flood salinization on the wider agri-food economy, drawing from the economic modelling results in Gould et al. (2020). It is acknowledged that biophysical impact of flood salinization is not limited to farmland (crop yields) but will have cascading negative consequences both backward (e.g. fertilizer, machinery suppliers) and forward (e.g. processing, distribution) along the supply chain. Based on the outputs of the model, Table 6.10 reports the results of a broader assessment of the impacts of a coastal flood salinization to the wider agrifood economy based on the flood year data alone.

The results suggest significant economic losses; total job losses and GVA across CZs is, respectively, approximately 944 and $£ 69$ million. Figure 6.8 summarizes the disaggregated impacts by sector, displaying total impacts across CZs. This figure shows that the greatest comparative losses are borne by food processing (£42 Million) followed by direct farm impacts in terms of loss in total Gross Margins (GM). These sectors similarly suffer higher losses in jobs; food processing jobs and direct farm losses amount to 348 and 407 respectively.

These costs are expected to be even higher when other cost components are added, e.g. environmental costs associated with salt-affected lands and the potential social cost of impaired farm businesses. Saline agriculture, as an adaptation strategy, has the potential to ameliorate these impacts. Future studies could assess the magnitude of the benefits afforded by saline agriculture adaptation. For example, increasing drought combined

\section{TABLE 6.10}

Wider Economy Impacts of Flood Salinization in Lincolnshire, UK: Jobs and Costs to Gross Margins (GM) or Gross Value Added (GVA) throughout the Food Value Chain

\begin{tabular}{clccccc} 
& At Risk & CZ1 & CZ2 & CZ3 & CZ4 & Total \\
Direct Farm & Jobs & 45 & 111 & 49 & 202 & 407 \\
Impacts & GM & $£ 1,341,985$ & $£ 3,339,480$ & $£ 1,482,514$ & $£ 6,058,340$ & $£ 12,222,319$ \\
Impact on & Jobs & 5 & 23 & 10 & 34 & 72 \\
Suppliers & GVA & $£ 287,134$ & $£ 1,340,610$ & $£ 577,601$ & $£ 1,968,726$ & $£ 4,174,071$ \\
Food & Jobs & 38 & 95 & 42 & 173 & 348 \\
Processing & GVA & $£ 4,615,120$ & $£ 11,484,552$ & $£ 5,098,403$ & $£ 20,834,779$ & $£ 42,032,854$ \\
Food & Jobs & 10 & 24 & 11 & 44 & 89 \\
Marketing & GVA & $£ 859,198$ & $£ 2,138,082$ & $£ 949,171$ & $£ 3,878,815$ & $£ 7,825,266$ \\
Food & Jobs & 3 & 7 & 3 & 13 & 26 \\
Logistics & GVA & $£ 256,614$ & $£ 638,574$ & $£ 283,486$ & $£ 1,158,473$ & $£ 2,337,147.00$ \\
Total & Jobs & 101 & 261 & 116 & 466 & 944 \\
& Jobs per ha & 0.07 & 0.09 & 0.08 & 0.09 & 0.08 \\
& Direct Losses & $£ 7,360,050$ & $£ 18,941,297$ & $£ 8,391,175$ & $£ 33,899,133$ & $£ 68,591,655$ \\
Multipliers & Jobs & 145 & 376 & 167 & 671 & 1359 \\
& GVA & $£ 10,598,472$ & $£ 27,275,468$ & $£ 12,083,292$ & $£ 48,814,752$ & $£ 98,771,984$ \\
& & & & & & \\
\hline
\end{tabular}




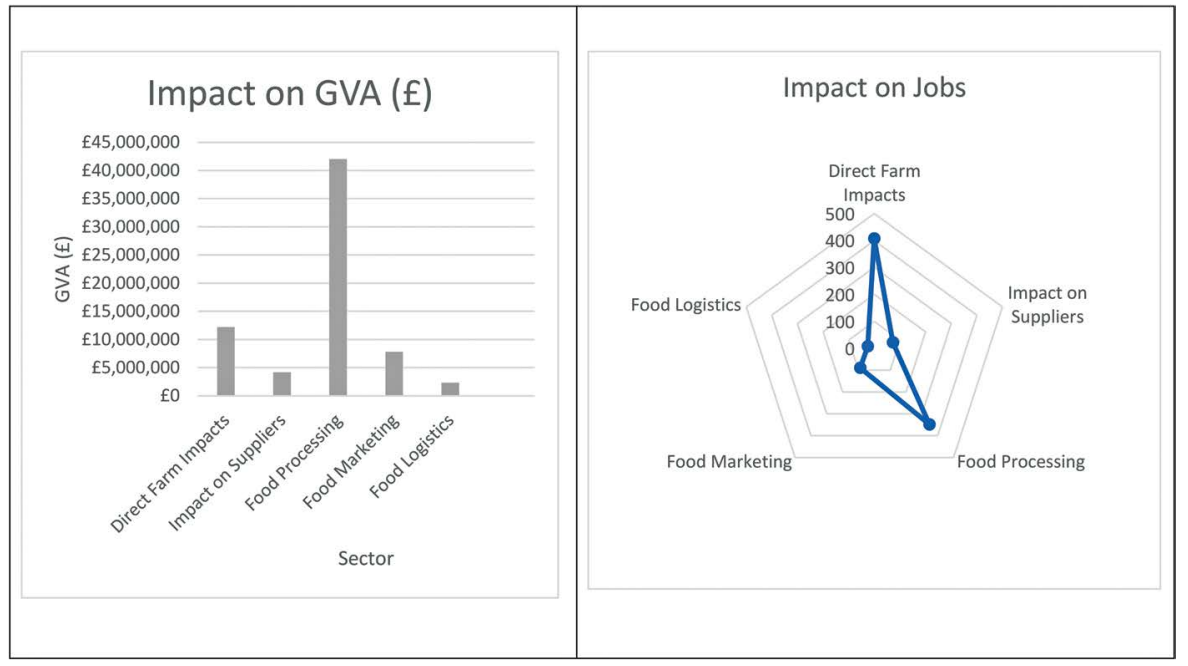

FIGURE 6.8 Wider economy impacts of flood salinization in Lincolnshire, UK.

with projected sea-level rises will lead to more sustained threats from salinization and create a sustained, long-term opportunity for salt-tolerant crop varieties.

\subsection{CONCLUSION}

This chapter provides an economic framework for risk assessment in regions where salinity poses a significant threat to agricultural production and the local/national economy. The chapter first reviewed the key literature on economic impacts of salinization and presented a conceptual methodological framework that could be applied to assessing such impacts, focusing on three typologies of salinization: irrigation salinization, seepage salinization and flood salinization. We conceptualized impact at different scales; farm-level, regional and wider economy scales. We then applied the framework, first to estimate crop yield and financial losses due to each salinity process. Subsequently, we scaled up the impact to regional or wider levels using data on affected areas and information on crop composition and distribution, where available. The analysis shows that there is significant economic impact of salinization.

Further, we find that the magnitude of the impact of salinization critically depend on a range of factors which include; the type of salinization process, the degree/ severity of salinity, the types (and value) of crops grown, farm-level decisions/ choices such as the use of salt-tolerant crops and other adaptation mechanisms as well as external shocks such as sea-level rise due to climate change. These factors may also be linked to spatial differences. For example, in a flood salinization case study in Lincolnshire, we found marked differences in flood resilience and the concomitant economic impact of salinity across CZs. The case study empirical results should provide is a "baseline" for economic costs of salinization that may inform future assessment of the potential of adaptation measures such as saline farming. 
Although it is widely acknowledged that salinization poses a significant problem to agriculture and the European economy now and in the future under climate change, there are limited data available on the extent and severity of salinization. This hinders accurate assessments of the biophysical and economic impacts of salinity and the potential for saline farming. Information on the economic risks and costs of salinization would be important inputs into priority setting and the formulation of policies aimed at building resilience to salinization in agricultural systems, including development of saline agriculture. There is an urgent need, therefore, to strengthen systems and mechanisms for monitoring soil salinity and associated risks.

\section{ENDNOTES}

1. There is a nuanced distinction between seed potato and potato for consumption. In this paper, "potato" refers to potato for consumption.

2. These results are limited to the impact of seepage salinity scenarios investigated in the study and do not suggest that seepage salinity is not a problem in the case study areas. For example, there is anecdotal evidence of significant crop losses due to seepage salinity in some regions of the Netherlands, particularly during the dry summers.

\section{REFERENCES}

Aslam, M., and Prathapar, S. A. 2006. Strategies to Mitigate Secondary Salinization in the Indus Basin of Pakistan: A Selective Review. Research Report 97. IWMI, Colombo, Sri Lanka.

Ayers, R. S., and Westcot, D. W. 1985. Water quality for agriculture. FAO Irrigation and Drainage Paper No. 29, Rome.

Bosello, F., Nicholls, R. J., Richards, J., Roson, R., and Tol, R. S. 2012. Economic impacts of climate change in Europe: Sea-level rise. Climatic Change 112: 63-81.

Daliakopoulos, I., Tsanis, I., Koutroulis, A., Kourgialas, N., Varouchakis, A., Karatzas, G., and Ritsema, C. 2016. The threat of soil salinity: A European scale review. Science of the Total Environment 573: 727-739.

de Vos, A., Bruning, B., Van Straten, G., Oosterbaan, R., Rozema, J., and Van Bodegom, P. 2016. Crop salt tolerance under controlled field conditions in The Netherlands, based on trials conducted at Salt Farm Texel. Salt Farm Texel.

De Waegemaeker, J. 2019. SalFar framework on salinization processes. A comparison of salinization processes across the North Sea Region. A report by ILVO for the Interreg VB North Sea Region project Saline Farming (SalFar).

FAO. 2011. The State of the World's Land and Water Resources for Food and Agriculture (SOLAW) - Managing Systems at Risk. Food and Agriculture Organization of the United Nations, Rome and Earthscan, London.

FAO and ITPS. 2015. Status of the World's Soil Resources (SWSR) - Main Report. Food and Agriculture Organization of the United Nations and Intergovernmental Technical Panel on Soils, Rome, Italy.

Ghassemi, F., Jakeman, A. J., and Nix, H. A. 1995. Salinisation of Land and Water Resources: Human Causes, Extent, Management and Case Studies. CAB International.

Gould, I. J., Wright, I., Collison, M., Ruto, E., Bosworth, G., and Pearson, S. 2020. The impact of coastal flooding on agriculture: A case study of Lincolnshire, United Kingdom. Land Degradation \& Development 31(2): 1545-1559.

Grattan, S. 2002. Irrigation Water Salinity and Crop Production, Publications by University of California, Division of Agriculture and Natural Resources. 
Hazelden, J., and Boorman, L. A. 2001. Soils and 'managed retreat' in south east England. Soil Use and Management 17: 150-154.

Janmaat, J. 2004. Calculating the cost of irrigation induced soil salinisation in the Tungabhadra project. Agricultural Economics 31(1): 81-96.

John, M., Pannell, D., and Kingwell, R. 2005. Climate change and the economics of farm management in the face of land degradation: Dryland salinity in Western Australia. Canadian Journal of Agricultural Economics 53(4): 443-459.

Koutroulis, A. G., Tsanis, I. K., Daliakopoulos, I. N., and Jacob, D. 2013. Impact of climate change on water resources status: A case study for Crete Island, Greece. Journal of Hydrology 479: 146-158.

Lipper, L., Thornton, P., Campbell, B. M., Baedeker, T., Braimoh, A., Bwalya, M., and Torquebiau, E. F. 2014. Climate - smart agriculture for food security. Nature Climate Change 4: 1068-1072.

Maas, E. V., and Hoffman, G. J. 1977. Crop salt tolerance - current assessment. Journal of Irrigation and Drainage Divison 103: 115-134.

Marshall, G.R. 2004. From words to deeds: enforcing farmers' conservation cost-sharing commitments. Journal of Rural Studies 20(2): 157-167.

Marshall, G. R., and Jones, R. E. 1997. Significance of supply response for estimating agricultural costs of soil salinity. Agricultural Systems 53(2-3): 231-252.

McCann, L. M. J., and Hafdahl, A.R. 2007. Agency perceptions of alternative salinity policies: The role of fairness. Land Economics 83(3): 331-352.

Montanarella, L. 2007. Trends in land degradation in Europe. In Climate and Land Degradation, ed. Sivakumar, V. K., and Ndiang'ui, N., 83-104. Springer, Berlin.

Negacz, K. 2018. Potential of Salt-tolerant Crop Production on Salinized, Degraded Lands. Masters dissertation, Vrije Universiteit Amsterdam, Netherlands.

Oldeman, L. R., Hakkeling, R. T. A., and Sombroek, W. G. 1991. World Map on Status of Human - Induced Soil Degradation. UNEP/International Soil Reference and Information Centre (ISRIC), Nairobi, Kenya.

Qadir, M., Quillérou, E., Nangia, V., et al. 2014. Economics of salt-induced land degradation and restoration. Natural Resources Forum 38(4): 282-295.

Redman, G. 2016. John Nix Farm Management Pocketbook (47th edition), Agro Business Consultants, Melton Mowbray.

Richards, J.A., and R. J. Nicholls. 2009. Impacts of climate change in coastal systems in Europe. PESETA-Coastal Systems study. EUR - Scientific and Technical Research Reports, Publications Office of the European Union.

Shannon, M., and Grieve, C. 1998. Tolerance of vegetable crops to salinity. Scientia Horticulturae 78: 5-38.

Tanji, K., and Kielen, N. 2002. Agricultural drainage water management in arid and semiarid areas. FAO Irrigation and Drainage Paper 61. FAO, Italy.

UN. 2015. Transforming our world: the 2030 Agenda for Sustainable Development: https:// www.refworld.org/docid/57b6e3e44.html [accessed 10 September, 2020].

van Straten, G., de Vos, A., Rozema, J., Bruning, B., and van Bodegom, P. 2019. An improved methodology to evaluate crop salt tolerance from field trials. Agricultural Water Management 213: 375-387.

Van Orshoven, J., Terres, J., and Tóth, T. 2012. Updated Common Bio-physical Criteria to Define Natural Constraints for Agriculture in Europe. EUR - Scientific and Technical Research series. Publications Office of the European Union, Luxembourg.

Winpenny, J., Heinz, I., and Koo-Oshima, S. 2010. The wealth of waste: The economics of wastewater use in agriculture. Food and Agriculture Organization of the United Nations, Rome, Italy.

Zekri, S., and Albisu, L. 1993. Economic impact of soil salinity in agriculture. A case study of Bardenas area, Spain. Agricultural Systems 41(3): 369-386. 